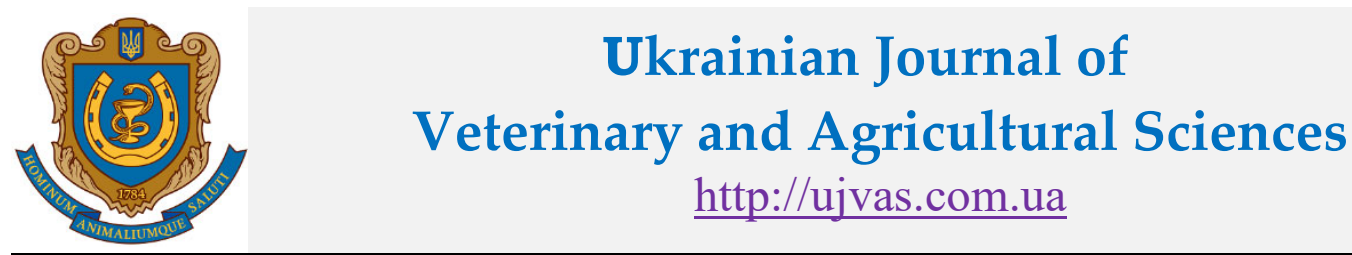

Stepan Gzhytskyi National University of Veterinary Medicine and Biotechnologies Lviv

\begin{tabular}{l|l|l} 
original article & UDC 619:636.7. 619:616-091 & doi: 10.32718/ujvas2-2.03
\end{tabular}

\title{
Morphofunctional changes in the heart and lung tissues of dogs for isoniazid poisoning
}

\author{
H. I. Kotsiumbas, N. P. Vretsona
}

Stepan Gzhytskyi National University of Veterinary Medicine and Biotechnologies Lviv, Pekarska Str., 50, Lviv, 79010, Ukraine

\begin{tabular}{|c|}
\hline $\begin{array}{l}\text { Article info } \\
\text { Received 06.09.2019 } \\
\text { Received in revised form } \\
\quad 14.10 .2019 \\
\text { Accepted } 15.10 .2019\end{array}$ \\
\hline $\begin{array}{l}\text { Correspondence author } \\
\text { Nataliya Vretsona } \\
\text { Tel.: +38-067-373-83-39 } \\
\text { E-mail: nataliya.vretsona@gmail.con }\end{array}$ \\
\hline $\begin{array}{l}\text { (C) } 2019 \text { Kotsiumbas H. I. \& } \\
\text { Vretsona N. P. This is an open- } \\
\text { access article distributed under the } \\
\text { terms of the Creative Commons } \\
\text { Attribution License, which permits } \\
\text { unrestricted use, distribution, and } \\
\text { reproduction in any medium, } \\
\text { provided the original author and } \\
\text { source are credited. }\end{array}$ \\
\hline$(\mathrm{cc}) \mathrm{BY}$ \\
\hline 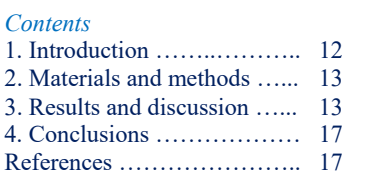 \\
\hline
\end{tabular}

\begin{abstract}
The article presents the results of macroscopic, histological and histochemical studies of the heart and lungs of dogs for isoniazid poisoning. A pathoanatomical section of 19 carcasses of dogs of different ages and breeds was performed; heart and lung fragments were selected for morphological examination. Heart and lung samples were fixed in $10 \%$ aqueous formalin neutral solution, Carnua and Buen fluids. Dehydration was carried out in ethanol of increasing concentration and embedded in paraffin. The sections were made on a MC-2 microtome $7 \mu \mathrm{m}$ thick, stained with hematoxylin and eosin, using the McManus and Brasche technique. Made histopreparations were examined under a Leica DM 2500 light microscope (Switzerland), photo-fixation was performed with a Leica DFC450C using Leica Application Suite Version 4.4 software. The results of morphohistochemical studies have shown that in acute poisoning of dogs with isoniazid in the heart prevailed acute disorders of the vascular circulation, manifested by a sharp expansion and destruction of the walls of the venous vessels, plasmorrhagia, microtromb of the capillaries and spasm of the arterioles, which led to the development of swelling, caused acute decrease of protein synthesation function of muscle fibers and dystrophic-necrobiotic changes of cardiomyocytes. It was noted, in the lungs of dogs on the background of acute congestive hyperemia, diapedesis of erythrocytes and accumulation of transudate in the lumen of the alveoli, foci of emphysema and bronchiectasis with rupture of the epithelial layer of the mucous membrane, elastic skeleton and muscular tubules of bronchial tubules that indicated the violation of gas exchange and the development of anoxemia. It is known that spontaneous isoniazid poisoning in dogs leads to an acute course and often fatal consequences. In the comprehensive study of the effects of chemicals on the body, and in particular isoniazid on the body of dogs, toxicological and pathomorphological studies are of great importance. The use of morphological and histochemical methods will reveal some of the mechanisms of intoxication.
\end{abstract}

Key words: dog, heart, lungs, microstructural changes, poisoning, isoniazid, histology, histochemistry.

\section{Citation:}

Kotsiumbas, H. I., \& Vretsona, N. P. (2019). Morphofunctional changes in the heart and lung tissues of dogs for isoniazid poisoning. Ukrainian Journal of Veterinary and Agricultural Sciences, 2(2), 12-17.

\section{Introduction}

For the purpose of poisoning stray, homeless animals in large cities isoniazid tablets alone or with food are dispensed around streets. At the same time, they can mix the preparation together with antiemetic drugs, which increases the possibility of the development of rapid poisoning of dogs with lethal consequences.

Due to the use of isoniazid as an anti-tuberculosis drug in medicine, its effect on dogs has not been sufficiently studied. According to the literature there are many scientific papers devoted to the study of the pharmacological properties of this drug, the therapeutic effect of isoniazid in the treatment of tuberculosis in both humans and animals. Moreover, antidote agents are known that should be used for possible isoniazid poisoning.

Currently, there are known cases of dog poisoning in experimental toxicosis with isoniazid and spontaneous poison- ing in both, different regions of Ukraine and abroad (Chin et al., 1978; Chin et al., 1981).

It is known that acute isoniazid poisoning in dogs leads to lethal consequences, primarily due to the destruction of the liver structure (Gurnani et al., 1992; Kotsyumbas \& Vretsona, 2018). This is due to the reactions of acetylation and hydrolysis of isoniazid to monoacetylhydrazines, which subsequently cause necrosis in the liver, heart and other organs (Villar et al., 1995). In addition, isoniazid inhibits the synthesis of nicotinamide dinucleotide (NAD) and disrupts oxidation and phosphorylation processes with the formation of severe metabolic acidosis (Shlapak \& Halushko, 2007). Due to the slow formation of NAD and NADP, which are derivatives of the vitamin nicotinamide and participate in the processes of tissue respiration, there is a permanent disruption of the respiratory chain and redox processes and, as a consequence, tissue hypoxia develops. 
In addition to the abovementioned, animal experiment also found that poisoning with hydrazine drugs, accompanied by the development of seizures (Kucenko, 2004; Kucenko et al., 2004), which suppresses the processes of inhibition in the CNS.

Spontaneous isoniazid poisoning in dogs leads to acute and often fatal effects. In the comprehensive study of the effects of chemicals on the body, and in particular isoniazid on the body of dogs, toxicological and pathomorphological studies are of great importance. The use of morphological and histochemical methods will reveal some of the mechanisms of intoxication.

\section{Materials and methods}

The pathoanatomical dissection and toxicological studies of pathological material from 19 carcasses of dogs of different age and breed were performed. During pathoanatomical incision, fragments of the heart muscle and lung were selected for morphological examination. The samples were fixed in $10 \%$ aqueous formalin neutral solution, Carnua and Buen fluids. Dehydration was carried out in ethanol of increasing concentration and embedded in paraffin (Merkulov, 1961). The sections were made on a MC-2 microtome $7 \mu \mathrm{m}$ thick, stained with hematoxylin and eosin, using the McManus and Brache method (Pirs, 1962). Made histopreparations were examined under a Leica DM 2500 light microscope (Switzerland), photo-fixation was performed with a Leica DFC450C using Leica Application Suite Version 4.4 software.

\section{Results and discussion}

During the autopsy of animals killed in isoniazid poisoning, a moderate enlargement of the right ventricle was observed macroscopically in the heart. Organ usually oval, coronary vessels dilated, overflowing with blood (Fig. 1). In some cases, small dot hemorrhages under the epicardium were noted, in others, only sharp coronary blood vessel filling. The heart cavities are also enlarged and overflowing with dark cherry blood clots. Endocardial moist, shiny. Heart muscle is light red in color, faint texture (Fig. 2).

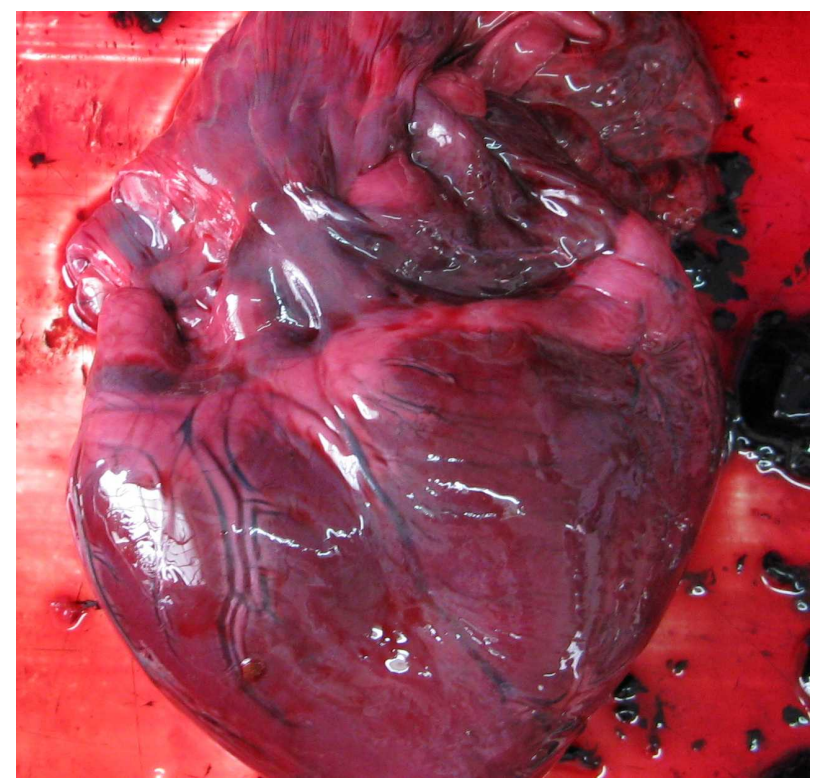

Fig. 1. Heart of the circular shape, coronary vessels dilated, overfilled with blood

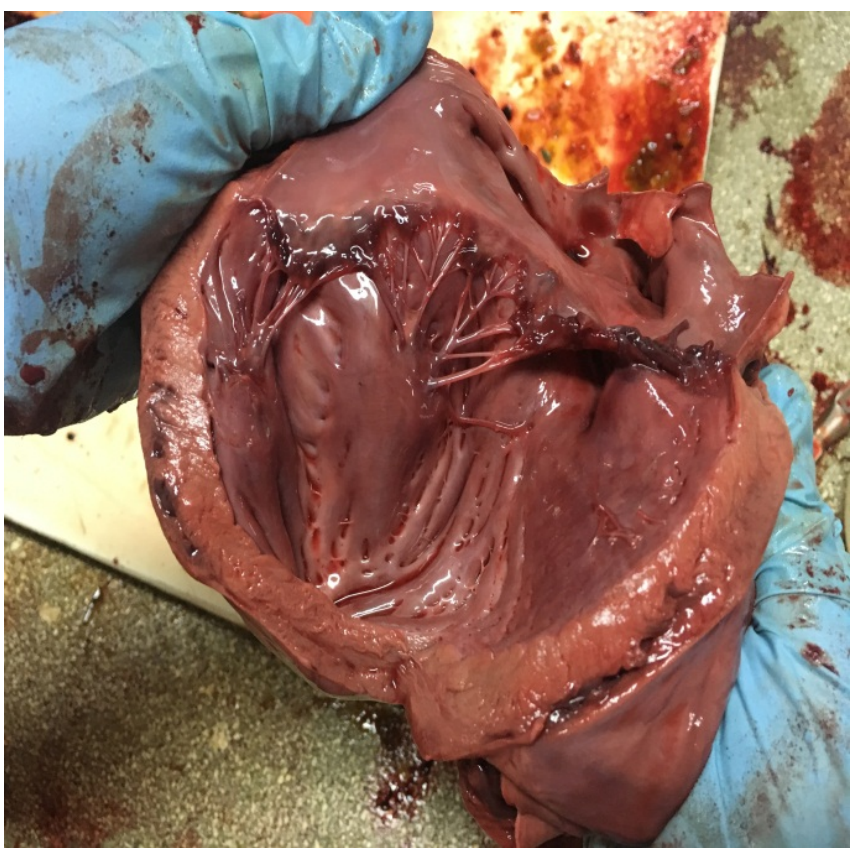

Fig. 2. Heart muscle is light red in color, with a faint texture

According to histological examination of the muscular tissue of the heart of dogs that died within 10-12 hours after poisoning, it was observed a significant disorders of hemocirculation, which were diffuse and manifested in fullblooded, diapedous hemorrhages. The lesions of the vessels of the microcirculatory bed were combined with the phenomena of paresis, capillary stasis. In the lumen of the capillaries, the uniform elements of the blood were poorly visualized as a result of their destruction. The lumen of the venous vessels is sharply expanded, filled with shaped elements of blood. In sharply expanded veins and venules, the structure of the inner elastic membrane is disturbed (Fig. 3).

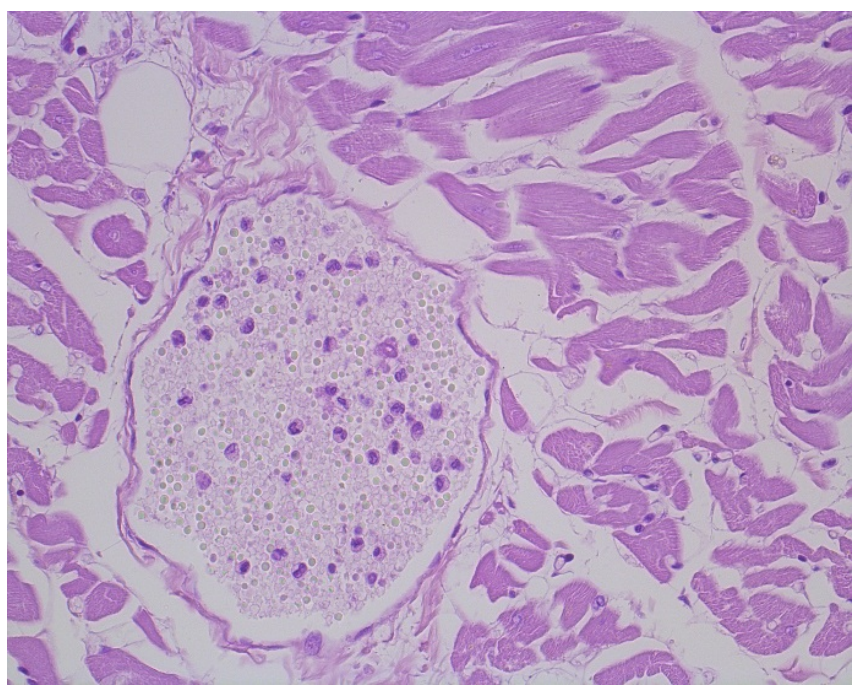

Fig. 3. Heart. The venous vessel is sharply enlarged, filled with shaped elements of blood. McManus. EP. 10, lens. 40

In some cases, in the lumen of the venous vessels thrombotic masses with aggregation and agglutination of red blood cells by type of soot phenomenon were revealed. Plasma impregnation of the walls of blood vessels, swelling of their elastic and argyrophilic fibers were noted. Around the vascular and intermuscular connective tissue stroma due to the destruction of collagen fibers and an increase in the content of glycoproteins, loosening and accumulation in the 
perivascular lumens of the transudata were noted. In arterioles, signs of spasm were: sharp tortuosity of the inner elastic membrane, external elastic fibers of the arteries are also tortuous, swollen, loose. In the smooth muscle fibers of the middle lining of the arteries, the nuclei of the nucleus are polymorphic, pale colored, enlarged, and small vacuoles were visible in the cytoplasm (Fig. 4).

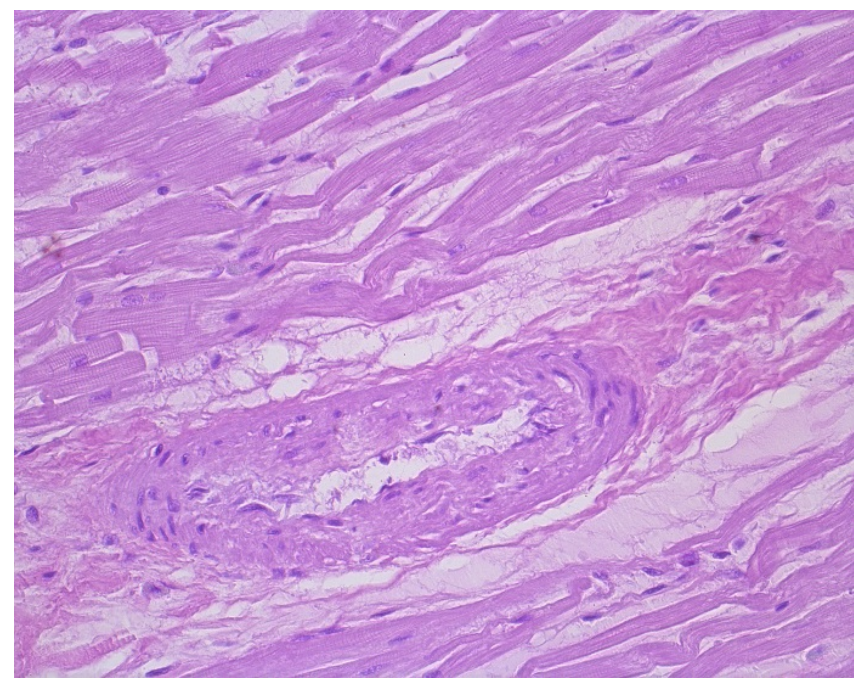

Fig. 4. Heart. In the arterioles, elastic twisting fibers are swollen, loose, and the cytoplasm of muscle fibers is enlightened. McManus. EP. 10, lens. 40

The connective tissue of the organ is impregnated with a glycoprotein-rich transudate, loosened (Fig. 5). In this case, most intermuscular lumens are filled with foamy, or homogeneous, low-fusinophilic protein mass. In the vast majority of muscle fibers have lost their transverse darkness, their structure is broken, the nuclei are lysed or in a state of pycnosis. Histostructural changes of myocardial cells were characterized by granular-deep decay and partial vacuolation of cardiomyocytes. The myocardium is more pronounced fragmentation and breakdown of muscle fibers, which indicated the prevalence of dystrophic-necrobiotic changes (Fig. 6).

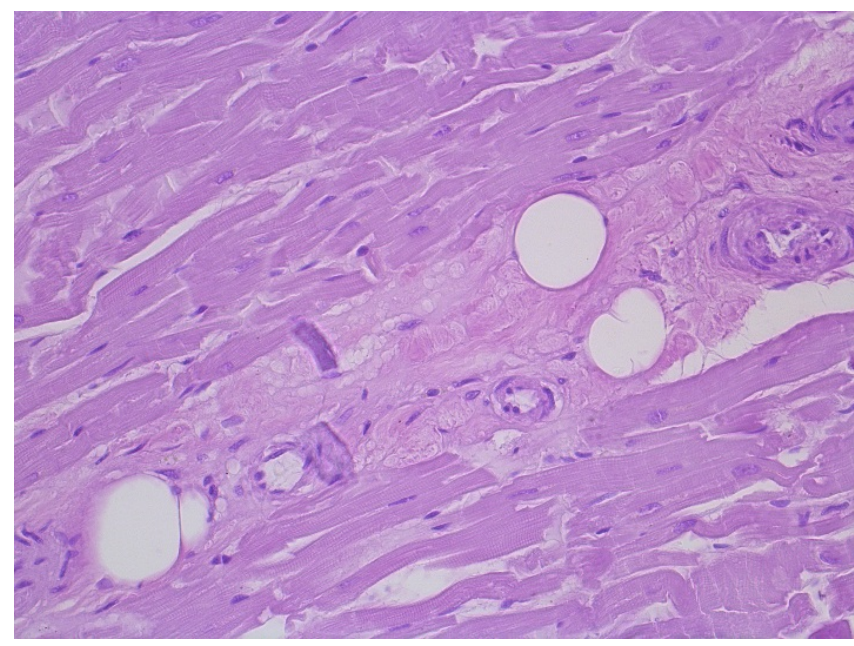

Fig. 5. Myocardium. The stroma of the organ is loosened, impregnated with a transudate rich in glycoproteins.

McManus. EP. 10, lens. 40

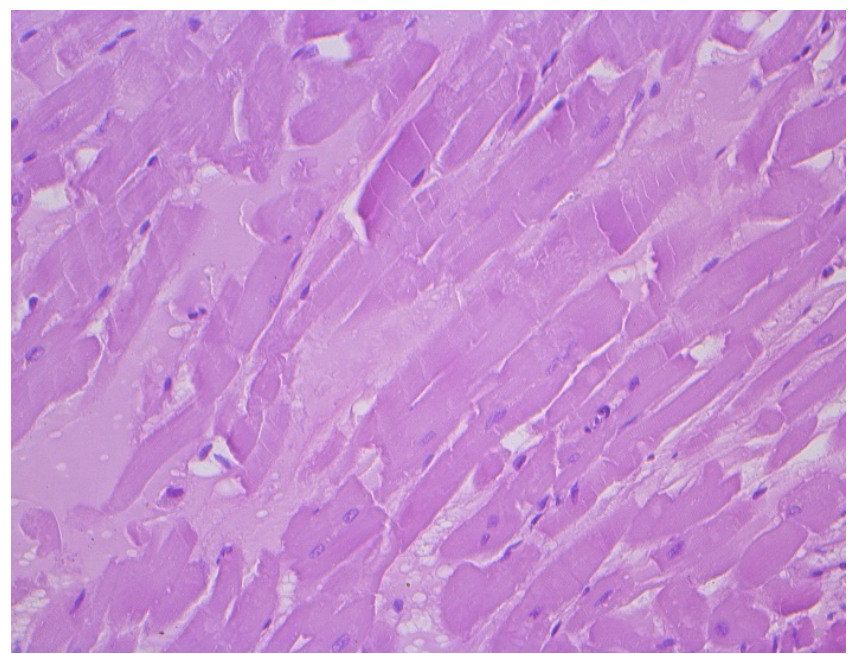

Fig. 6. Myocardium. Granular-deep decay of cardiomyocytes. McManus. EP. 10, lens. 40

A sharp decrease in RNA content was noted in cardiomyocytes, on preparations stained with Brasche. Muscle fibers did not absorb pyronin, which indicated a dramatic decrease in the cardiomyocyte's proteinsynthetic function and their vital functions (Fig. 7). The single muscle fibers showed poorly stained nuclei with methylene green, which also indicated the progression of lytic processes in the muscle fibers. The paint was most absorbed by nuclei of lymphocytes and histiocytes, which were individually placed between the muscle fibers (Fig. 8).

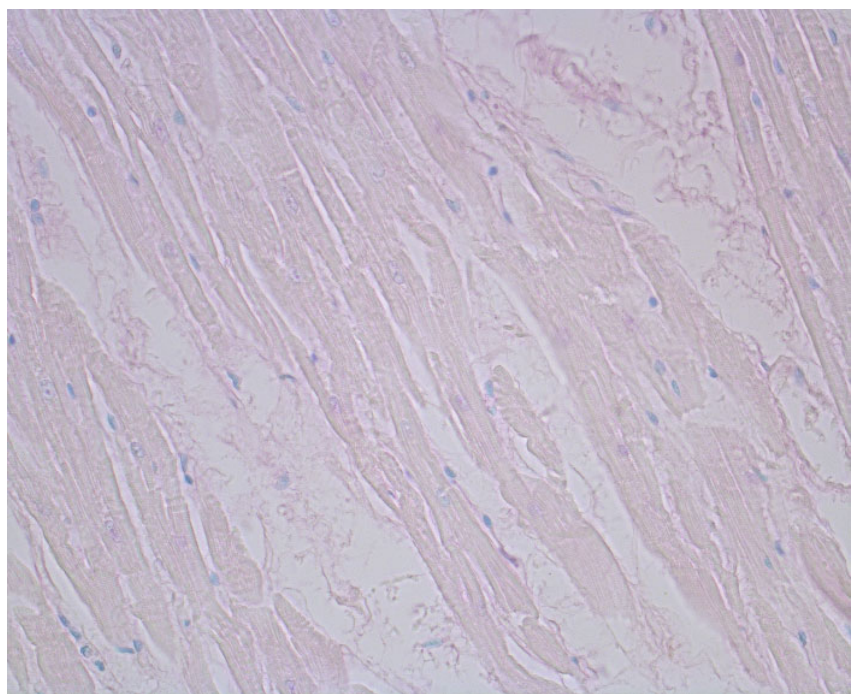

Fig. 7. Heart. Swollen stromal. A sharp decrease in RNA content in cardiomyocytes. Muscle fiber cross-hair loss. Brache. EP 10, lens. 40

The results of morphohistochemical studies indicate that with acute poisoning of dogs with isoniazid in the heart, all structural and functional elements of the organ are involved in the pathological process. Disorders of the vascular circulation were manifested by the sharp expansion and destruction of the walls of the venous vessels, plasmorrhagia, microtubules of the capillaries and spasm of arterioles leading to edema, a sharp decrease in the cardiomyocyte function of white and synthetic function and the development of dystrophic-necrobiotic changes. Macroscopically, the lungs of dogs for isoniazid poisoning are blood-stained, heterogeneously colored: cherry-red, sometimes with pink patches slightly protruding above the organ surface and dark-cherry 
ones that have deeply penetrated the lungs. In the section from the lumen of the bronchi, foamy-bloody fluid was released (Figs. 9, 10). Pieces of lungs thrown into the water were submerged. In some animals, the airway lumen contained a considerable amount of translucent, viscous fluid.

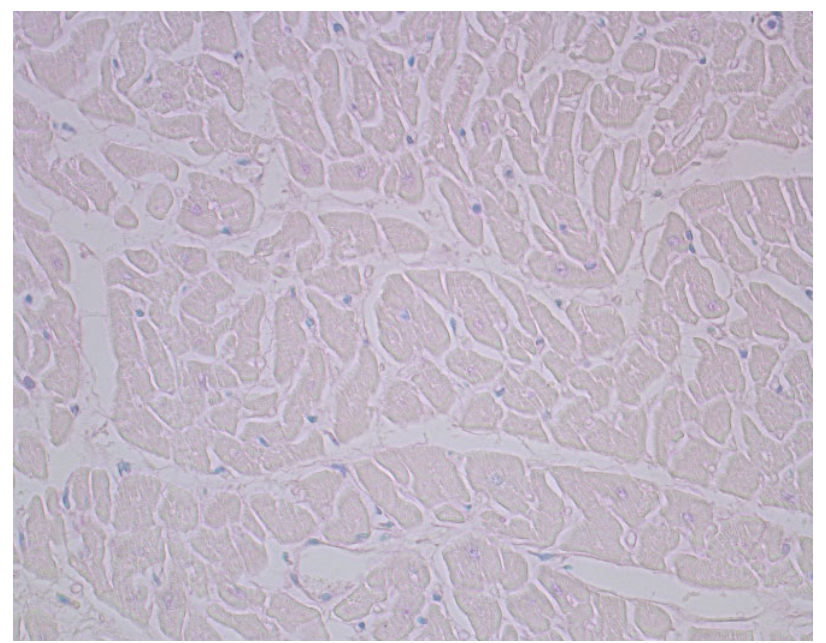

Fig. 8. Heart. Single lymphocytes and histiocytes between muscle fibers. Brache. EP 10, lens 40

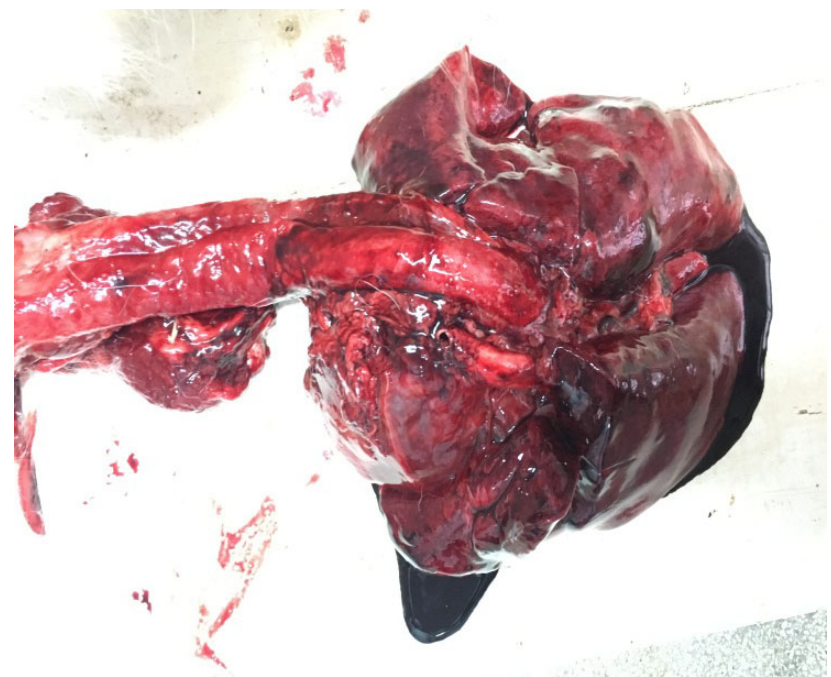

Fig. 9. Lungs of cherry-red color, foamy-bloody fluid was emitted from the lumen of the bronchi

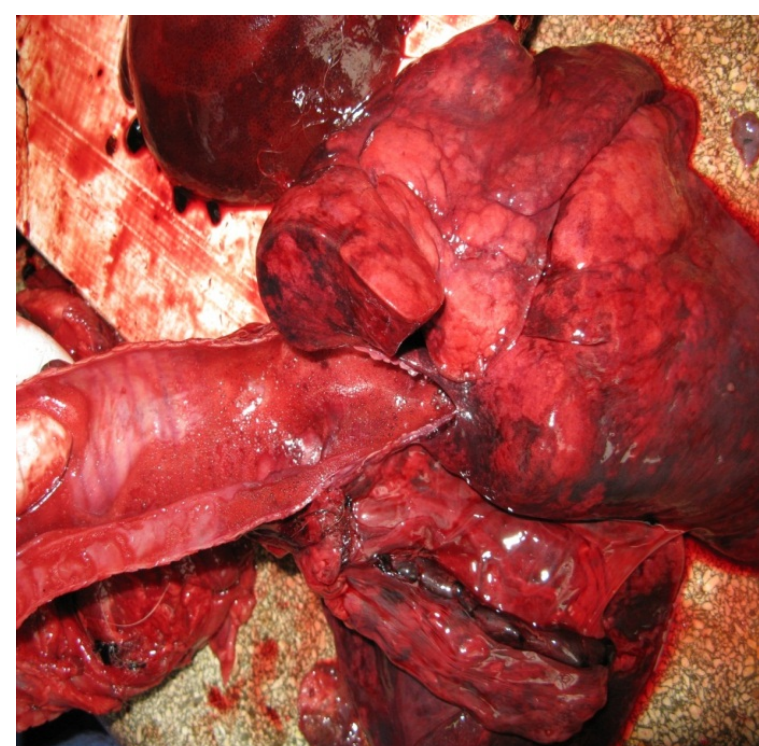

Fig. 10. The lungs are heterogeneously colored: red, sometimes with pink and dark cherry areas
In histological examination of the lung tissue of dogs noted acute congestive hyperemia with diapedesis of erythrocytes in the lumen of the alveoli and edema. Changes on the part of small interparticle veins were expressed in sharp expansion of a lumen, disturbance of structure of an internal elastic membrane. The lumen of the capillaries of the lungs is also greatly expanded. The vascular endothelium is swollen, the cytoplasm is enlightened, in places it is peeled away. The stroma around the vessels is swollen, there is a stratification of connective tissue fibers (Fig. $11 \mathrm{~A}, \mathrm{~B}$ ).

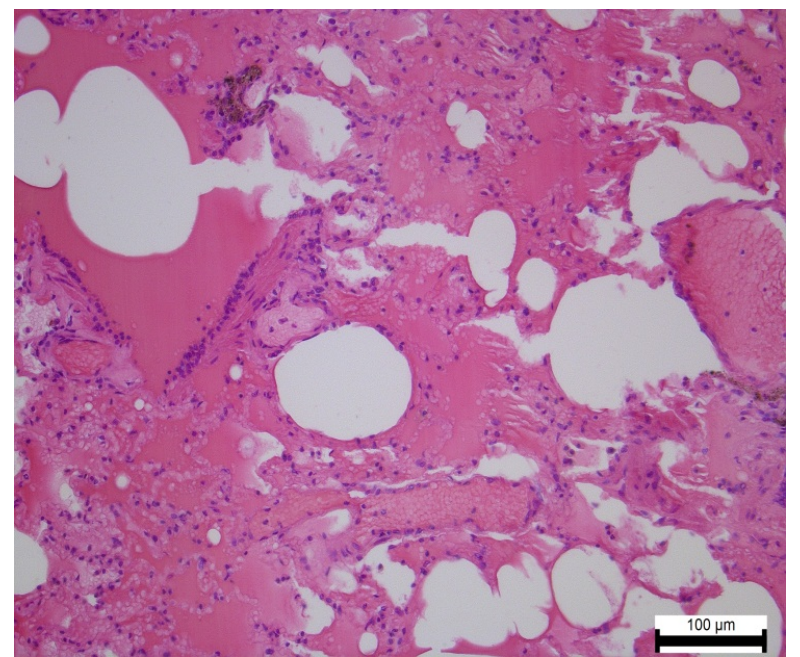

Fig. 11 A. Lungs. Acute congestive hyperemia. Hematoxylin and eosin (b). EP 10, lens 20

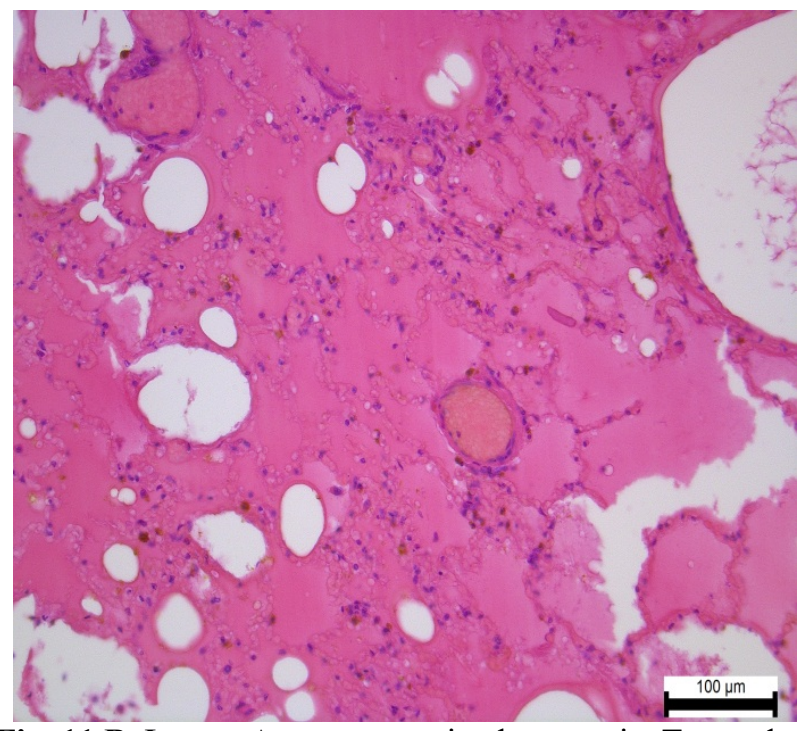

Fig. 11 B. Lungs. Acute congestive hyperemia. Transudate and erythrocytes filled the lumen of the alveoli. Hematoxylin and eosin (b). EP 10, lens 20

The arteries of the level of the respiratory and terminal bronchi are enlarged, overflowing with erythrocytes. The vast majority of the epithelium of the alveolar walls is swollen, the cytoplasm is swollen, the nucleus is in a state of lysis and rex (Fig. 12 A). The lumps of the alveoli of some lobules are filled with transudate, the other lobes are of moderate fine-grained, fuchsinophilic content. The alveoli foci with strongly stretched and thin and torn walls were found. In such areas the interveolar pores are enlarged, the gaps of the capillaries are empty. Single lymphocytes and macrophages were seen in the emphysematous areas of the lymphocytes in the emphysematous areas of the Brashe 
stained preparations. The cytoplasm of the respiratory epithelium is weakly stained with pyronin (Fig. 12. B).

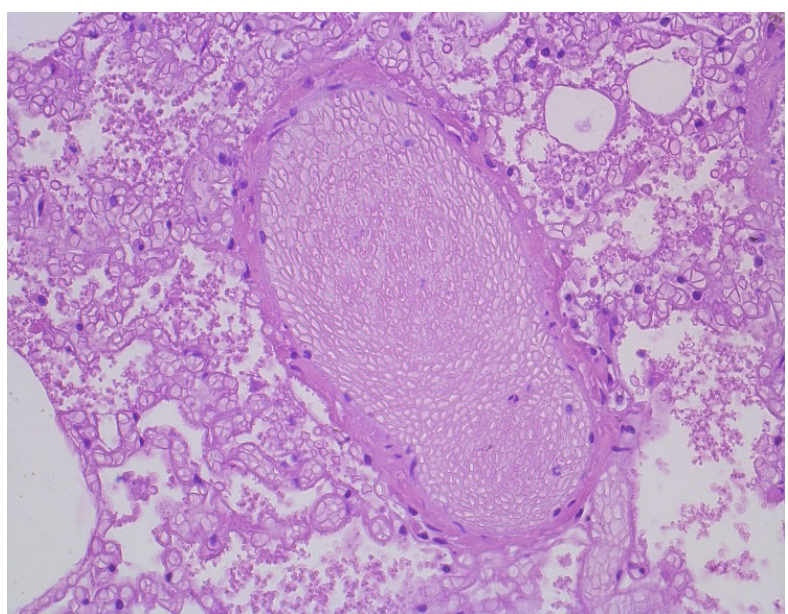

Fig. 12 A. Lungs. The artery is filled with red blood cells. McManus EP 10, lens 40

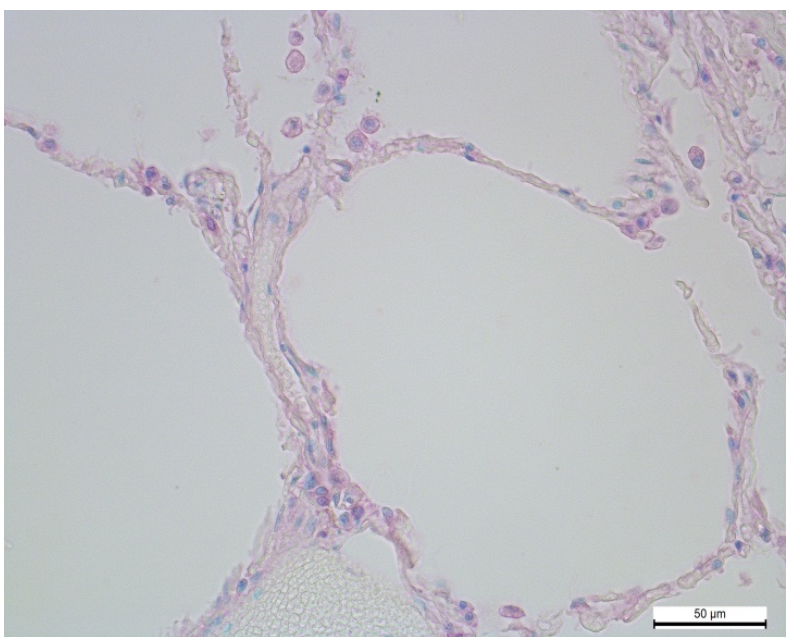

Fig. 12 Б. Acute expansion of the lumen of the alveoli. Single lymphocytes and macrophages in the lumen of enlarged alveoli. Brache. EP 10, lens 40

In other animals there was a sharp destruction of the walls of the capillaries, small vessels, which led to intense infiltration of the alveoli by erythrocytes. (Fig. 13 A). Around the vessels in the stroma of the organ revealed a cluster of macrophages, the cytoplasm of which is filled with brown pigment hemosiderin (Fig. $13 \mathrm{~B}$ ).

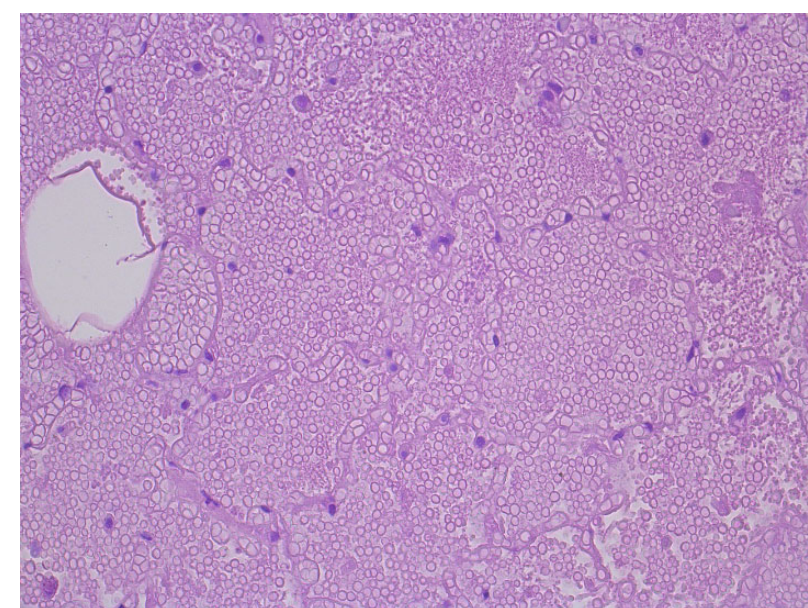

Fig. 13 A. Lungs. The alveoli are filled with red blood cells. McManus. EP 10, lens 20

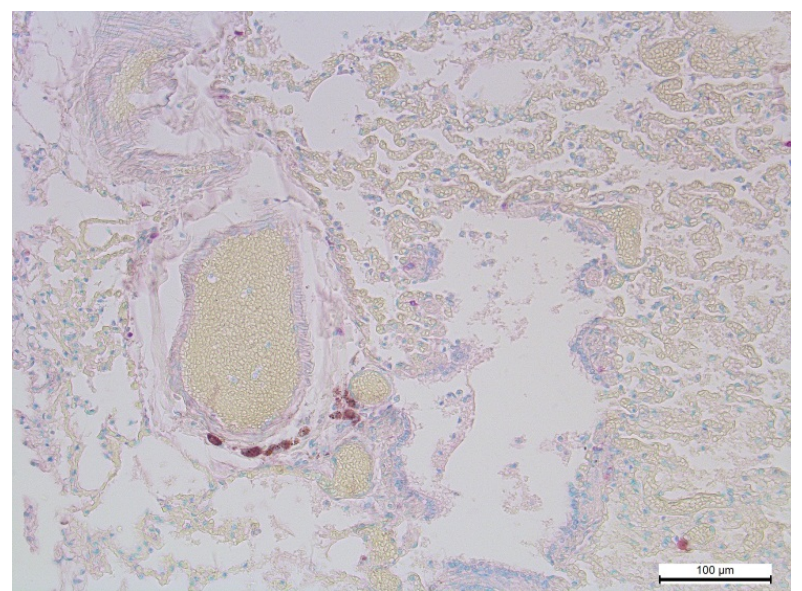

Fig. 13 B. Lungs. Single lymphocytes and macrophages in the lumen of the enlarged alveoli. Brache. EP 10, lens 20

A sharp disturbance of gas exchange in the lungs of dogs was indicated by marked changes in bronchi of different caliber. In some dogs in the middle-caliber bronchi in the lumen showed a small content of transudate. In this case, the epithelial layer of the mucous membrane is represented as a single-row cylindrical epithelium, which is mainly swollen (Fig. 14 A, B). Cell cytoplasm is often vacuolated, nuclei in a state of lysis, pycnosis, even the rejection of entire layers of the bronchial cover has been observed.

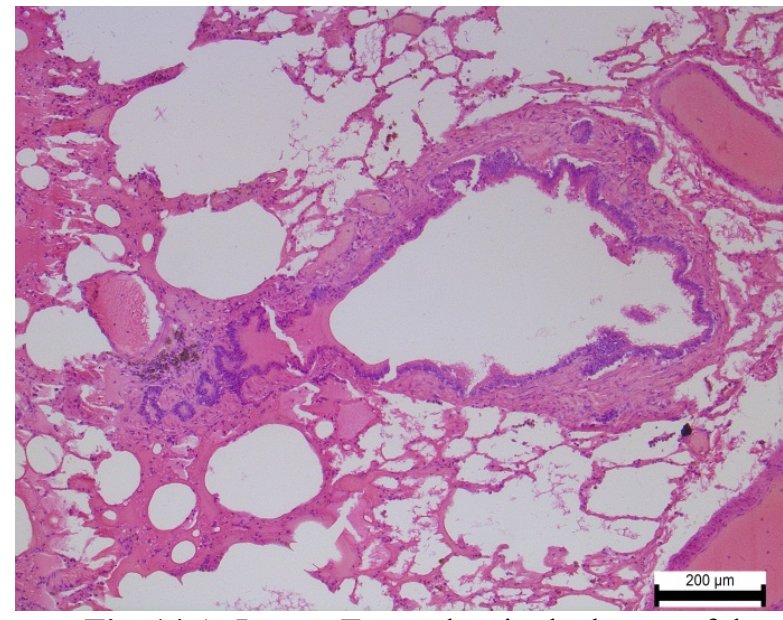

Fig. 14 A. Lungs. Transudate in the lumen of the bronchus. The cylindrical epithelium of the mucous membrane is swollen, the cytoplasm is vacuolated. Hematoxylin and eosin. EP 10, lens 10

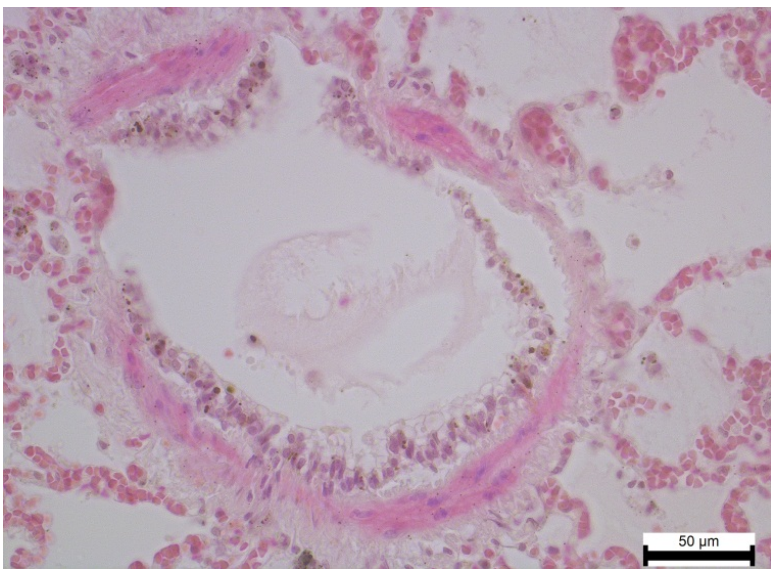

Fig. 14 B. Lungs. Transudate in the lumen of the bronchus. Disorders of the bronchus. Hematoxylin and eosin. EP 10, lens 40 
In small bronchial tubes and bronchioles acute diffuse enlargement of their lumen prevailed, causing a considerable thinning of their walls. These changes were due to the intensified inspiratory air of the animal and its pressure on the walls of the bronchioles. Highly expressed bronchiectasis was accompanied by a violation and rupture of the epithelial layer of the mucous membrane, elastic skeleton and muscular bundles of the walls of small bronchi (Fig. 15 A, B).

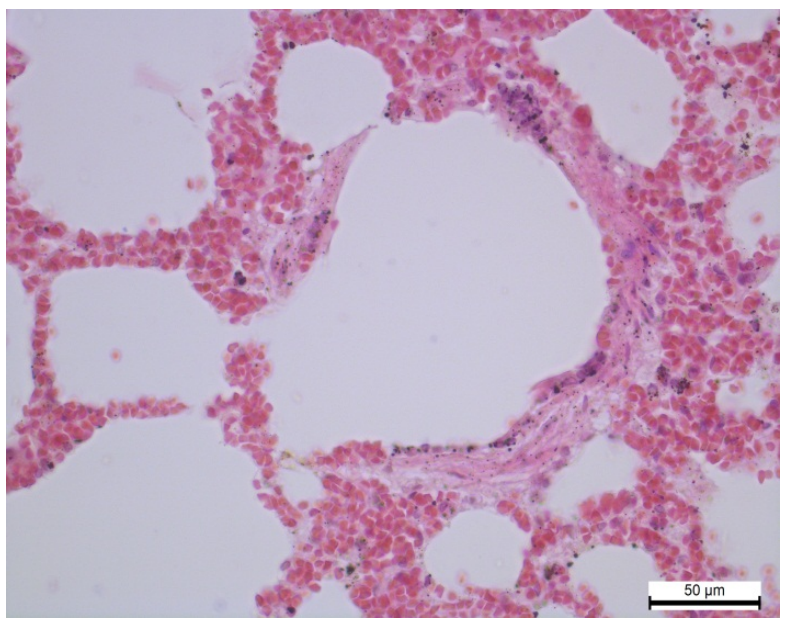

Fig. 15 A. Lungs. Bronchiectasis with a rupture of the bronchial wall. Hematoxylin and eosin. EP 10, lens 40

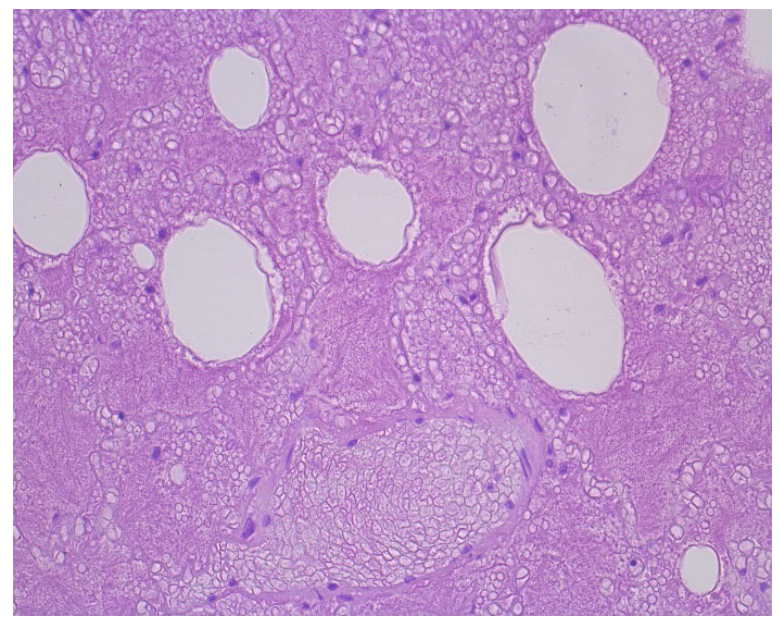

Fig. 15 B. Lungs. Bronchiectasis with a rupture of the wall of the bronchioles. McManus. EP 10, lens 40

Thus, in the lungs of dogs for isoniazid poisoning were revealed the following: a sharp disturbance of gas exchange, which was accompanied by acute congestive hyperemia with diapedesis of erythrocytes and transudate in the lumen of the alveoli, foci of emphysema and bronchiectasis with disturbance and rupture of the epithelial plaque, bronchial tubes.

\section{Conclusions}

The results of morphohistochemical studies showed that in acute poisoning of dogs with isoniazid in the heart, acute disorders of the vascular circulation prevailed, which were manifested by a sharp expansion and destruction of the walls of the venous vessels, plasmorrhagia, microthromb of capillaries, and spasm of arterioles, leading to arterioles spasm, necrobiotic changes of cardiomyocytes.

It was noted diapedesis of erythrocytes and accumulation of transudate in the lumen of the alveoli, foci of emphysema and bronchiectasis with rupture of the epithelial layer of the mucous membrane, elastic skeleton and muscular ducts of bronchial tubules in the lungs of dogs on the background of acute congestive hyperemia.

\section{References}

Chin, L., Sievers, M. L., Herrier, R. N., \& Picchioni, A. L. (1981). Potentiation of pyridoxine by depressants and anticonvulsants in the treatment of acute isoniazid intoxication in dogs. Toxicol Appl Pharmacol, 58(3), 504-509. doi: 10.1016/0041008X(81)90103-4.

Chin, L., Sievers, M. L., Laird, H. E., Herrier, R. N., \& Picchioni, A. L. (1978). Evaluation of diazepam and pyridoxine as antidotes to isoniazid intoxication in rats and dogs. Toxicol Appl Pharmacol, 45(3), 713-722. doi: 10.1016/0041008X(78)90164-3.

Gurnani, A., Chawla, R. \& Kundra, P. (1992). Acute isoniazid poisoning. Anaesthesia, 47, 781-783.

Kotsyumbas, H.I., \& Vretsona, N.P. (2018). Histological and histochemical changes in the dogs liver at poisoning isoniazid. Scientific Messenger of Lviv National University of Veterinary Medicine and Biotechnologies, 20(92), 197-202. doi: 10.32718/nvlvet9241.

Kucenko, S. A. (2004). Osnovy toksikologii. SPb.: Foliant (in Russian).

Kucenko, S. A., Butomo, N. V., Grebenjuk, A. N. i dr. (2004). Voennaja toksikologija, radiobiologija i medicinskaja zashhita. $\mathrm{SPb}$.: Foliant (in Russian).

Merkulov, G. A. (1961). Kurs patologogistologicheskoj tehniki. Medgiz, 104-107 (in Russian).

Pirs, Je. (1962). Gistohimija teoreticheskaja i prikladnaja. M.: Inostr. lit. (in Russian).

Shlapak, I. P., \& Halushko, O. A. (2007). Vitaminy yak antydoty v intensyvnii terapii hostrykh otruien. Bil, zneboliuvannia $i$ intensyvna terapiia, 1, 3-4 (in Ukrainian).

Villar, D., Knight, M. K., Holding, J., Barret, G. H., \& Buck, W. B. (1995). Treatment of acute isoniazid overdose in dogs. Veterinary and Human Toxicology, 37, 473-477. https://www.ncbi.nlm.nih.gov/pubmed/8592842. 